\title{
Consumo de nutrientes e desempenho de cordeiros alimentados com dietas que contêm diferentes níveis de fibra em detergente neutro*
}

\author{
Intake of nutrients and performance of lambs fed with diets containing different levels of neutral \\ detergent fiber
}

\author{
Adriano Ramos Cardoso ${ }^{1}$ Cléber Cassol Pires ${ }^{2}$ \\ Sérgio Carvalho ${ }^{3}$ Diego Barcelos Galvani ${ }^{4}$ Felipe Jochims ${ }^{4}$ \\ Marcel Hastenpflug ${ }^{4}$ Tatiana Pfüller Wommer ${ }^{4}$
}

RESUMO

Este estudo foi conduzido no Departamento de Zootecnia da Universidade Federal de Santa Maria, RS, no período de agosto a dezembro de 2003. O objetivo foi avaliar o consumo de nutrientes e o desempenho de cordeiros machos, não castrados, cruzados Ile de France x Texel, submetidos a quatro níveis de fibra em detergente neutro (FDN): $25 \%, 31 \%$, $37 \%$ e $43 \%$. O volumoso utilizado foi a silagem de sorgo híbrido (AG 2005 E) e o concentrado foi composto de milho em grão triturado, farelo de soja, sal comum, calcário calcítico e fosfato bicálcico. As dietas dos quatro tratamentos eram isoprotéicas, contendo $17 \%$ de proteína bruta. Foram utilizados 20 cordeiros desmamados em média aos 42 dias de idade e abatidos quando atingiram $30 \mathrm{~kg}$ de peso vivo. $O$ delineamento experimental foi o inteiramento casualizado, com quatro tratamentos e cinco repetições. Foram avaliados os consumos de nutrientes, o ganho de peso médio diário (GMD), a conversão alimentar (CA) e o número de dias que os cordeiros levaram para atingir o peso vivo ao abate de $30 \mathrm{~kg}$. A adição de níveis crescentes de FDN à dieta ocasionou um decréscimo linear nos consumos de matéria seca, matéria orgânica, proteína bruta, extrato etéreo, carboidratos totais e carboidratos não estruturais. Por outro lado, aumentou linearmente o consumo de fibra em detergente neutro e fibra em detergente ácido. Verificou-se redução linear do GMD e piora na CA com o aumento do teor de fibra na ração, o que proporcionou uma elevação linear no número de dias que os cordeiros levaram para atingir o peso de abate.

Palavras-chave: confinamento, eficiência alimentar, fibra, ovinos.

\section{ABSTRACT}

This study was conducted at the Animal Science Department of Federal University of Santa Maria, RS, from
August to December 2003. The aim was to evaluate the food intake and performance of male lambs, non-castrated, crossbreed Ile de France $x$ Texel, submitted to four levels of NDF: $25 \%, 31 \%, 37 \%$ and $43 \%$. The roughage used was a hybrid sorghum silage ( $A G 2005 \mathrm{E}$ ) and the concentrate was composed of ground corn, soybean meal, common salt, limestone and dicalcium phosphate. The four diets were isoproteic with $17 \%$ of crude protein. Twenty lambs, with an average of 42 days old were used in the experiment and slaughtered when they reach $30 \mathrm{~kg}$ live weight. The experimental design was completely ramdomized, with four treatments and five replications. The intake of nutrients, daily average weigh gain $(D W G)$ feed conversion $(F C)$ and the number of days to the reachr $30 \mathrm{~kg}$ of live weight were evaluated. The addition of increasing levels of NDF to the diet caused a linear decrease in the intake of dry matter (DMI), organic matter (OMI), crude protein (CPI), ethereal extract (EEI), total carbohydrates (TCHOI) and non-structural carbohydrates (NSCI). On the other hand, the consumption of neutral detergent fiber (NDFI) and acid detergent fiber (ADFI) increased linearly with the increase of NDF in the diets. The increase of the fiber level in the diet resulted in linear reduction in $D W G$ and in $F C$, which caused a linear increase in the amount of days to lambs reach the slaughter weight.

Key words: feeding efficiency, feedlot, fiber, sheep.

\section{INTRODUÇÃO}

A baixa qualidade das carcaças comercializadas, geralmente provenientes de animais com idade avançada, é o principal fator limitante a influenciar o consumo de carne ovina no Brasil (SILVA \& PIRES, 2000; GARCIA et al., 2000). No entanto, tem-

\footnotetext{
${ }^{1}$ Curso de Pós - graduação em Zootecnia, UFSM, Santa Maria, RS, Brasil. E - mail: zootarc@terra.com.br.

${ }^{2}$ Departamento de zootecnia, UFSM, Campus Camobi, CEP 97105-900, Santa Maria, RS, Brasil. E - mail:cpires@ccr.ufsm.com.br. Autor para correspondência

${ }^{3}$ Centro Universitário Feevale, Novo Hamburgo, RS, Brasil. E - mail: sergiocarvalho@ feevale.br.

${ }^{4}$ Curso de Zootecnia, UFSM, Santa Maria, RS, Brasil.
} 
se observado uma tendência crescente de intensificação dos sistemas produtivos, objetivando redução na idade de abate e produção de carcaças de melhor qualidade, opondo-se aos sistemas tradicionais de terminação a pasto (MACEDO et al., 2000; SIQUEIRA \& FERNANDES, 2000).

TURINO (2003) relatou que os modernos sistemas de produção de cordeiros devem enfatizar, concomitantemente, os aspectos econômicos e qualitativos da carne, salientando, ainda, que geralmente os programas de confinamento apresentam elevados custos com alimentação. A formulação de ração balanceada para ovinos tem por objetivo principal o fornecimento de quantidades adequadas de nutrientes resultando, assim, em melhor desempenho e/ou produtividade animal, sendo um ponto crítico determinar a relação ótima entre o volumoso e concentrado que compõem a dieta total.

De acordo com PIRES et al (2000), o consumo de alimento possui grande importância dentro de sistemas de produção de carne, visto que será a partir da ingestão de matéria seca que ocorrerá o fornecimento da quantidade de nutrientes necessários para atender os requerimentos de mantença e de produção dos animais. O termo ingestão voluntária refere-se à quantidade máxima de matéria seca (MS) ingerida pelo animal espontaneamente. A capacidade de um alimento ser ingerido pelo animal depende da ação de vários fatores que interagem em diferentes situações de alimentação, comportamento animal e meio ambiente (THIAGO \& GILL, 1990). A predição da ingestão em ruminantes é extremamente importante e difícil, devido às interações que ocorrem entre o animal e a dieta, existindo poucos dados disponíveis para subsidiar o uso de equações (FORBES, 1995).

A fibra insolúvel em detergente neutro (FDN) representa a fração de carboidratos estruturais dos alimentos (parede celular) e tem sido relacionada à regulação da ingestão de alimentos, taxa de passagem e atividade mastigatória dos ruminantes. Dietas com elevada concentração de fibra, necessariamente, possuem baixa densidade energética e a repleção ruminal limita a ingestão, reduzindo a performance animal. Por outro lado, dietas com baixa concentração de fibra, também podem resultar em menor ingestão total de MS, uma vez que as exigências energéticas do animal são supridas em níveis mais baixos de ingestão (VAN SOEST \& MERTENS, 1984). Além disso, apresentam fermentação ruminal sub-ótima, aumentando os riscos de acidose, pondo em risco a performance e a saúde animal (MERTENS, 1996).

LOERCH (1997) considerou as exigências de fibra para animais confinados e destinados ao abate como de menor importância, pois esses são alimentados com dietas que contêm alta proporção de concentrado e por um período de tempo relativamente curto. Porém, embora dietas com até $100 \%$ de concentrado tenham sido utilizadas com sucesso para bovinos e ovinos de corte, a adição de uma fonte de fibra na proporção de 5 a $20 \%$ da MS da dieta faz com que ocorra uma melhoria no desempenho animal (PRESTON, 1998).

A utilização de um nível adequado de FDN, na ração, visa obter máxima produção, utilizando-se o máximo de volumoso sem, entretanto, provocar restrição na ingestão alimentar pelo efeito do enchimento do trato gastrintestinal, com conseqüente comprometimento do desempenho e elevação do tempo necessário para atingir o peso de abate. No entanto, estudos referentes à influência de diferentes níveis de FDN na dieta sobre consumo de nutrientes e desempenho de cordeiros em confinamento são ainda escassos no Brasil.

Assim, o presente trabalho foi realizado com o objetivo de avaliar o efeito de níveis crescentes de FDN na dieta sobre o consumo de nutrientes e o desempenho de cordeiros terminados em confinamento.

\section{MATERIAL E MÉTODOS}

O experimento foi conduzido no setor de Ovinocultura, do Departamento de Zootecnia da Universidade Federal de Santa Maria (UFSM), localizada fisiograficamente na Depressão Central do Estado do Rio Grande do Sul, no período compreendido entre agosto e dezembro de 2003. Conforme a classificação de Köppen, o clima da região é o Cfa (subtropical úmido), com precipitação média anual de $1.769 \mathrm{~mm}$, temperatura média anual de $19,2^{\circ} \mathrm{C}$, média mínima de $9,3^{\circ} \mathrm{C}$ em julho e média máxima de $24,7^{\circ} \mathrm{C} \mathrm{em}$ janeiro, insolação de 2.212 horas anuais com umidade relativa do ar de 82\% (MORENO, 1961).

Foram utilizados 20 cordeiros, machos não castrados, provenientes do cruzamento das raças Ile de France e Texel. Os animais, após o nascimento, permaneceram com suas respectivas mães em pastagem natural e receberam suplementação concentrada em sistema de creep feeding a partir dos 15 dias de idade. O suplemento utilizado foi composto por grão de milho quebrado (Zea mays L.) e farelo de soja (Glycine Max L.) em mistura, de forma a compor $18 \%$ de PB (MS). O desmame ocorreu em média aos 42 dias de idade, ocasião na qual os cordeiros foram distribuídos aleatoriamente em quatro tratamentos, sendo: 25, 31, 37 e $43 \%$ de FDN. Os animais foram alojados em baias individuais, com área de $2 \mathrm{~m}^{2}$ providas de comedouros e bebedouros. Na ocasião, foi realizada vermifugação para o controle de endoparasitas, sendo o tratamento repetido quando necessário, após coleta de fezes 
realizada diretamente na ampola retal dos cordeiros, para contagem do número de ovos por grama de fezes, segundo metodologia de MATOS \& MATOS (1988).

Antes do início do período experimental, os animais passaram por um período de adaptação (7 dias), em que receberam, ad libitum, uma dieta contendo de $35 \%$ de FDN e $17 \%$ de PB. Após este período, passouse a fornecer a dieta correspondente a cada tratamento. A alimentação foi fornecida duas vezes ao dia, em horários preestabelecidos às 8:00 e às 16:00 horas, ajustada de forma a manter as sobras em $10 \%$ do oferecido. $\mathrm{O}$ alimento utilizado foi composto por silagem de sorgo (Sorghum bicolor (L.) Moench), grão de milho quebrado (Zea mays L.), farelo de soja (Glycine Max L.) e mistura mineral. As proporções entre volumoso e concentrado variaram de forma a se obterem os níveis de FDN desejados. As rações utilizadas foram calculadas para serem isoprotéicas, com $17 \%$ de PB (MS). As proporções dos ingredientes utilizados na formulação das rações e a composição bromatológica da silagem e dos concentrados utilizados nas dietas experimentais encontram-se na tabela 1 .

Durante o experimento foram coletadas amostras dos alimentos fornecidos e das respectivas sobras, as quais foram identificadas e acondicionadas em freezer, para posteriores análises laboratoriais. Todas as amostras foram pré-secadas em estufa ventilada a $65^{\circ} \mathrm{Ce}$, posteriormente, moídas em moinho tipo "Willey" com peneira de $1 \mathrm{~mm}$. A seguir, foram acondicionadas em frascos identificados, para determinação de matéria seca (MS), matéria orgânica (MO), cinzas (CIN), fibra em detergente neutro (FDN), fibra em detergente ácido (FDA), proteína bruta (PB) e extrato etéreo (EE), segundo SILVA (1990). Os carboidratos totais (CHT) dos alimentos fornecidos e das sobras foram calculados segundo SNIFFEN et al. (1992), em que CHT (\%) = 100 $(\% \mathrm{~PB}+\% \mathrm{EE}+\% \mathrm{CIN})$, e os carboidratos não-estruturais (CNE), pela diferença de CHT - FDN.

Os animais foram pesados no início do período experimental e a cada intervalo de 21 dias, com jejum prévio de sólidos por 12 horas. $\mathrm{O}$ abate foi realizado por intermédio de sangria, seccionando-se os grandes vasos do pescoço, assim que os animais atingiram $30 \mathrm{~kg}$ de peso vivo.

O delineamento experimental utilizado foi o inteiramente casualizado com quatro tratamentos e cinco repetições, sendo que cada cordeiro foi considerado uma unidade experimental. Os dados foram submetidos à análise de variância e regressão, com auxílio do pacote estatístico SAS (SAS, 1997). Para análise de regressão, foi utilizada, como variável independente, o nível de FDN consumido pelos animais, sendo 23, 29, 36 e 44\% da MS. O modelo adotado, segundo o grau da polinomial, foi selecionado de acordo com a significância do teste $\mathrm{F}$ e coeficientes de regressão, adotando-se o nível de 5\% de probabilidade.

\section{RESULTADOS E DISCUSSÃO}

Os resultados referentes à média de consumo de MS, MO, PB, EE, FDN, FDA, CHT e CNE, expressos em quilograma por dia (kg/dia), porcentagem de peso vivo (\%PV) e gramas por unidade de tamanho metabólico $\left(\mathrm{g} / \mathrm{kg}^{0,75}\right)$, os respectivos coeficientes de variação e determinação e as equações de regressão são apresentados, respectivamente, nas tabelas 2,3 e 4.

Os valores de consumo de MS, MO, PB, EE, CHT e CNE expressos em $\mathrm{kg} / \mathrm{dia}, \% \mathrm{PV}$ e $\mathrm{g} / \mathrm{kg}^{0,75}$, diminuíram linearmente $(\mathrm{P}<0,01)$ com o incremento dos níveis de FDN nas dietas. Por outro lado, os consumos de FDN e FDA, nas diversas formas em que foram expressos, apresentaram comportamento linear crescente $(\mathrm{P}<0,01)$ com o aumento do nível de FDN nas dietas.

As médias de consumo de MS durante todo o período experimental, de forma geral, encontram-se abaixo da média recomendada pelo NRC (1985) para ovinos desta categoria, a qual varia de 1,0 a 1,3kg MS/ animal/dia. ROCHA (2002), trabalhando com cordeiros Santa Inês, alimentados com dietas isoenergéticas (72,8\% NDT) e níveis crescentes de PB $(14,16,18$ e $20 \%$ de PB), sendo o nível de FDN médio de $25 \%$, verificou consumo médio de $0,950 \mathrm{~kg} \mathrm{MS} / \mathrm{animal} / \mathrm{dia}$, semelhante ao encontrado no presente trabalho para os níveis de 25 e $31 \%$ de FDN na dieta $(0,968$ e $0,959 \mathrm{~kg}$ / animal/dia, respectivamente), porém superior aos observados nos níveis de 37 e $43 \%$, que foram de 0,773 e $0,765 \mathrm{~kg} / \mathrm{animal} / \mathrm{dia}$, respectivamente.

O consumo crescente de FDN e FDA pode ser explicado pelos seus respectivos teores, expressos na base da matéria seca total das rações (tabela 1), que cresceram linearmente com o aumento da porcentagem de volumoso na dieta. Estes resultados estão em desacordo com RESENDE et al. (1994), os quais citam que sendo a parede celular um componente do alimento que limita a ingestão, os animais possuem capacidade máxima de ingestão de FDN constante. Por outro lado, os resultados encontrados no presente trabalho são semelhantes aos verificados por BÜRGER et al. (2000) e ARAÚJO et al. (1998), os quais trabalharam com bovinos, bem como aos encontrados por CARVALHO (2002) o qual testou diferentes níveis de FDN (20, 27 , 34,41 e $48 \%$ na MS) na dieta de cabras em fase de lactação.

Na tabela 5, são apresentadas as médias dos valores referentes ao peso inicial, peso ao abate, dias 
Tabela 1 - Proporções dos ingredientes (\% MS) utilizados na formulação das rações e média dos teores de matéria seca (MS), matéria orgânica (MO), proteína bruta (PB), extrato etéreo (EE), fibra em detergente neutro (FDN), fibra em detergente ácido (FDA), carboidratos totais (CHT), carboidratos não estruturais (CNE), cinzas (CIN), energia digestível (ED), cálcio (Ca) e fósforo (P), da silagem e dos concentrados utilizados na composição das dietas experimentais.

\begin{tabular}{|c|c|c|c|c|c|}
\hline \multirow[b]{2}{*}{ Item $\%$} & \multicolumn{5}{|c|}{ Tratamentos } \\
\hline & 25 & 31 & 37 & 43 & \\
\hline Silagem de Sorgo & 33,09 & 47,31 & 61,55 & 75,78 & \\
\hline Milho Quebrado & 45,15 & 30,30 & 15,43 & 0,58 & \\
\hline Farelo de Soja & 20,03 & 20,78 & 21,54 & 22,33 & \\
\hline Calcário Calcítico & 1,13 & 0,90 & 0,68 & 0,45 & \\
\hline Fosfato Bicálcico & 0,00 & 0,11 & 0,20 & 0,30 & \\
\hline \multirow[t]{2}{*}{ Sal comum } & 0,60 & 0,60 & 0,60 & 0,60 & \\
\hline & \multicolumn{5}{|c|}{ Concentrados } \\
\hline Item $\%$ & 25 & 31 & 37 & 43 & Silagem \\
\hline MS & 89,39 & 89,21 & 89,23 & 89,78 & 35,52 \\
\hline MO & 94,94 & 94,33 & 93,36 & 91,01 & 94,94 \\
\hline PB & 19,85 & 25,06 & 31,12 & 40,56 & 6,25 \\
\hline $\mathrm{EE}$ & 2,84 & 2,44 & 2,61 & 2,58 & 2,55 \\
\hline FDN & 11,60 & 10,90 & 11,30 & 14,90 & 53,70 \\
\hline FDA & 1,50 & 1,30 & 1,50 & 3,90 & 27,90 \\
\hline CHT & 72,08 & 66,73 & 59,42 & 47,75 & 85,82 \\
\hline CNE & 60,65 & 55,93 & 48,33 & 32,97 & 32,44 \\
\hline $\mathrm{CIN}$ & 5,06 & 5,67 & 6,64 & 8,9 & 5,06 \\
\hline ED (Mcal/kg) & 3,87 & 3,66 & 3,90 & 3,76 & 2,51 \\
\hline $\mathrm{Ca}$ & 0,68 & 0,76 & 0,90 & 1,18 & 0,34 \\
\hline $\mathrm{P}$ & 0,41 & 0,48 & 0,60 & 0,87 & 0,17 \\
\hline
\end{tabular}

Tabela 2 - Médias dos valores de consumo de matéria seca (CMS), matéria orgânica (CMO), proteína bruta (CPB), extrato etéreo (CEE), fibra em detergente neutro (CFDN), fibra em detergente acido (CFDA), carboidratos totais (CCHT) e carboidratos não estruturais $(\mathrm{CCNE})$, expressos em $\mathrm{kg} / \mathrm{dia}$, coeficientes de variação $(\mathrm{CV})$, equações de regressão (ER) e coeficientes de determinação $\left(\mathrm{R}^{2}\right)$, de acordo com o nível de FDN.

\begin{tabular}{|c|c|c|c|c|c|c|c|}
\hline \multirow[b]{2}{*}{ Variáveis } & \multicolumn{4}{|c|}{ NÍVEL DE FDN } & \multirow[b]{2}{*}{$\mathrm{R}^{2}$} & \multirow[b]{2}{*}{$\mathrm{CV}(\%)$} & \multirow[b]{2}{*}{ ER } \\
\hline & 25 & 31 & 37 & 43 & & & \\
\hline CMS & 0,968 & 0,959 & 0,773 & 0,765 & 0,72 & 6,85 & 1 \\
\hline $\mathrm{CMO}$ & 0,919 & 0,907 & 0,729 & 0,719 & 0,73 & 6,82 & 2 \\
\hline $\mathrm{CPB}$ & 0,156 & 0,164 & 0,128 & 0,115 & 0,77 & 7,49 & 3 \\
\hline CEE & 0,027 & 0,024 & 0,020 & 0,020 & 0,72 & 6,97 & 4 \\
\hline CFDN & 0,223 & 0,278 & 0,280 & 0,336 & 0,78 & 7,44 & 5 \\
\hline CFDA & 0,078 & 0,112 & 0,122 & 0,154 & 0,88 & 8,51 & 6 \\
\hline $\mathrm{CCHT}$ & 0,734 & 0,717 & 0,578 & 0,581 & 0,70 & 7,06 & 7 \\
\hline CCNE & 0,513 & 0,440 & 0,299 & 0,247 & 0,94 & 7,43 & 8 \\
\hline
\end{tabular}

$1-\mathrm{CMS}=1,25-0,012 \mathrm{FDN}^{* *}$

$2-\mathrm{CMO}=1,19-0,011 \mathrm{FDN}^{* *}$

$3-\mathrm{CPB}=0,219-0,002 \mathrm{FDN}^{* *}$

$4-\mathrm{CEE}=0,033-0,0003 \mathrm{FDN} * *$

$5-\mathrm{CFDN}=0,119+0,005 \mathrm{FDN} * *$

$6-\mathrm{CFDA}=0,005+0,003 \mathrm{FDN} * *$

$7-\mathrm{CCHT}=0,940-0,009 \mathrm{FDN} * *$

$8-\mathrm{CCNE}=0,822-0,013 \mathrm{FDN}^{*} *$

** significativo a $1 \%$ de probabilidade pelo teste $\mathrm{F}$.

$\mathrm{FDN}=$ nível de fibra em detergente neutro da dieta.

Ciência Rural, v.36, n.1, jan-fev, 2006. 
Tabela 3 - Médias dos valores de consumo de matéria seca (CMS), matéria orgânica (CMO), proteína bruta (CPB), extrato etéreo (CEE), fibra em detergente neutro (CFDN), fibra em detergente acido (CFDA), carboidratos totais (CCHT) e carboidratos não estruturais (CCNE), expressos em \% PV, coeficientes de variação (CV), equações de regressão (ER) e coeficientes de determinação ( $\left.\mathrm{R}^{2}\right)$, de acordo com o nível de FDN.

\begin{tabular}{|c|c|c|c|c|c|c|c|}
\hline \multirow[b]{2}{*}{ Variáveis } & \multicolumn{4}{|c|}{ NÍVEL DE FDN } & \multirow[b]{2}{*}{$\mathrm{R}^{2}$} & \multirow[b]{2}{*}{$\mathrm{CV}(\%)$} & \multirow[b]{2}{*}{ ER } \\
\hline & 25 & 31 & 37 & 43 & & & \\
\hline CMS & 3,80 & 3,73 & 3,19 & 3,12 & 0,46 & 9,60 & 1 \\
\hline $\mathrm{CMO}$ & 3,61 & 3,53 & 3,01 & 2,93 & 0,48 & 9,59 & 2 \\
\hline $\mathrm{CPB}$ & 0,61 & 0,64 & 0,53 & 0,47 & 0,59 & 9,39 & 3 \\
\hline CEE & 0,10 & 0,10 & 0,09 & 0,09 & 0,38 & 10,18 & 4 \\
\hline CFDN & 0,87 & 1,08 & 1,16 & 1,37 & 0,69 & 10,68 & 5 \\
\hline CFDA & 0,30 & 0,44 & 0,50 & 0,63 & 0,83 & 11,62 & 6 \\
\hline CCHT & 2,88 & 2,79 & 2,38 & 2,37 & 0,44 & 9,79 & 7 \\
\hline CCNE & 2,01 & 1,71 & 1,23 & 1,01 & 0,89 & 9,67 & 8 \\
\hline
\end{tabular}

$1-\mathrm{CMS}=4,69-0,037 \mathrm{FDN}^{* *}$

$2-\mathrm{CMO}=4,49-0,037 \mathrm{FDN} * *$

$3-\mathrm{CPB}=0,82-0,008 \mathrm{FDN}^{*} *$

$4-\mathrm{CEE}=0,124-0,0009 \mathrm{FDN} * *$

$5-\mathrm{CFDN}=0,38+0,022 \mathrm{FDN} * *$

$6-\mathrm{CFDA}=-0,023+0,015 \mathrm{FDN} * *$

$7-\mathrm{CCHT}=3,53-0,028 \mathrm{FDN} * *$

$8-\mathrm{CCNE}=3,15-0,05 \mathrm{FDN} * *$

** significativo a $1 \%$ de probabilidade pelo teste $\mathrm{F}$

FDN = nível de fibra em detergente neutro da dieta.

Tabela 4 - Médias dos valores de consumo de matéria seca (CMS), matéria orgânica (CMO), proteína bruta (CPB), extrato etéreo (CEE), fibra em detergente neutro (CFDN), fibra em detergente acido (CFDA), carboidratos totais (CCHT) e carboidratos não estruturais $(\mathrm{CCNE})$, expressos em $\mathrm{g} / \mathrm{kg}^{0,75}$, coeficientes de variação $(\mathrm{CV})$, equações de regressão $(\mathrm{ER})$ e coeficientes de determinação $\left(\mathrm{R}^{2}\right)$, de acordo com o nível de FDN.

\begin{tabular}{|c|c|c|c|c|c|c|c|}
\hline \multirow[b]{2}{*}{ Variáveis } & \multicolumn{4}{|c|}{ NÍVEL DE FDN } & \multirow[b]{2}{*}{$\mathrm{R}^{2}$} & \multirow[b]{2}{*}{$\mathrm{CV}(\%)$} & \multirow[b]{2}{*}{ ER } \\
\hline & 25 & 31 & 37 & 43 & & & \\
\hline CMS & 85,34 & 83,99 & 70,77 & 66,91 & 0,62 & 8,05 & 1 \\
\hline $\mathrm{CMO}$ & 81,03 & 79,45 & 66,74 & 62,89 & 0,64 & 8,04 & 2 \\
\hline $\mathrm{CPB}$ & 13,82 & 14,38 & 11,77 & 10,06 & 0,68 & 8,48 & 3 \\
\hline CEE & 2,36 & 2,15 & 1,89 & 1,81 & 0,64 & 8,09 & 4 \\
\hline CFDN & 19,66 & 24,38 & 25,66 & 29,46 & 0,69 & 9,29 & 5 \\
\hline CFDA & 6,89 & 9,83 & 11,15 & 13,58 & 0,84 & 10,34 & 6 \\
\hline $\mathrm{CCHT}$ & 64,69 & 62,77 & 52,89 & 50,85 & 0,61 & 8,24 & 7 \\
\hline CCNE & 45,18 & 38,54 & 27,41 & 21,56 & 0,92 & 8,12 & 8 \\
\hline
\end{tabular}

$1-\mathrm{CMS}=110,19-1,02 \mathrm{FDN}^{* *}$

$2-\mathrm{CMO}=105,26-0,99 \mathrm{FDN}^{* *}$

$3-\mathrm{CPB}=19,20-0,20 \mathrm{FDN}^{*} *$

$4-\mathrm{CEE}=2,98-0,03 \mathrm{FDN}^{*} *$

$5-\mathrm{CFDN}=10,33+0,43 \mathrm{FDN}^{*} *$

$6-\mathrm{CFDA}=0,24+0,31 \mathrm{FDN} * *$

$7-\mathrm{CCHT}=82,94-0,77 \mathrm{FDN} * *$

$8-\mathrm{CCNE}=72,73-1,20 \mathrm{FDN}^{*} *$

** significativo a $1 \%$ de probabilidade pelo teste $\mathrm{F}$.

FDN = nível de fibra em detergente neutro da dieta. 
para atingir o peso de abate, ganho de peso diário e conversão alimentar, de acordo com o nível de FDN das dietas. O peso vivo ao desmame com média de 19,28kg, é superior ao encontrado por MOTTA (2000), que verificou para cordeiros da raça Texel em confinamento desmamados aos 45 dias com acesso ao creep feeding, valores médios de $13,39 \mathrm{~kg}$. Por outro lado, o peso ao desmame aos 42 dias, quando comparado ao encontrado por PIRES et. al. (2000), é semelhante, sendo que esses autores encontraram um valor médio de $19,94 \mathrm{~kg}$.

O aumento do teor de fibra na dieta dos cordeiros promoveu redução linear no ganho de peso diário dos cordeiros, sendo que houve uma redução de $41,40 \%$ quando se passou do nível de $25 \%$ para $43 \%$ de FDN. O maior GMD dos cordeiros com baixos níveis de FDN explica-se pela maior quantidade de concentrado e, consequientemente, de energia na dieta fornecida aos animais.

A redução do GMD verificada com o aumento do teor de FDN das dietas proporcionou um aumento linear do número de dias em que os cordeiros levaram para atingir o peso de abate estabelecido. Verifica-se que, para cada unidade percentual de adição de fibra na dieta, houve um aumento de 1,75 dias para atingir o peso de abate. No entanto as médias de GMD observadas nos níveis de 25 e $31 \%$ de FDN encontramse próximas, podendo assim, o nível de $31 \%$ de FDN ser o mais adequado, uma vez que esta dieta, por possuir maior quantidade de volumoso (tabela 1), torna-se mais barata. Este é um aspecto importante a ser considerado, principalmente quando se trabalha em sistemas intensivos de produção de cordeiros para abate.

A CA piorou em $38,5 \%$ quando o nível da dieta variou de $25 \%$ para o nível de $43 \%$ de FDN. Cabe salientar, no entanto, que, com exceção da CA observada ao nível de $43 \%$ de FDN, os valores encontrados no presente trabalho são muito bons. Segundo BUENO et al. (2004), o incremento na proporção de concentrado na dieta melhora linearmente a CA, em função da maior concentração de nutrientes digestíveis. Estes autores relataram médias de CA que variaram entre 3,20 e 4,98, semelhantes ao deste trabalho para o menor e o maior nível de FDN, respectivamente, sendo que, naquele estudo, os níveis de FDN variaram entre 44,9 a $56,7 \%$. É importante ressaltar que estes autores trabalharam com silagem de milho que, segundo NICHOLS et al. (1998), apresenta coeficiente de digestibilidade aparente das frações FDN e PB superior aos da silagem de sorgo. FURUSHO-GARCIA et al. (2004), trabalhando com cordeiros de diferentes genótipos alimentados com dietas que contêm $80 \%$ de concentrado $(21,47 \%$ de FDN) observaram conversão alimentar de 3,20, semelhante à encontrada no represente trabalho para os níveis de 25,31 e $37 \%$ de FDN na dieta.

\section{CONCLUSÕES}

Os consumos de MS, MO, PB, EE, CHT e CNE diminuem linearmente com o aumento do teor de FDN da dieta, ao passo que os consumos de FDN e FDA elevam-se linearmente. O aumento do nível de fibra da dieta de cordeiros confinados provoca redução do ganho médio diário e redução na eficiência de conversão alimentar, elevando, consequentemente, o número de dias para alcançar o peso de abate. Contudo, o nível de $31 \%$ de FDN na dieta mostra-se mais adequado para terminação de cordeiros desmamados.

Tabela 5 - Médias dos valores de peso inicial (PI), peso ao abate (PA), dias para atingir o peso de abate (Dias), ganho de peso diário (GMD) e conversão alimentar (CA), coeficientes de variação (CV), equações de regressão (ER) e coeficientes de determinação $\left(\mathrm{R}^{2}\right)$, de acordo com o nível de FDN.

\begin{tabular}{|c|c|c|c|c|c|c|c|}
\hline \multirow[b]{2}{*}{ Variáveis } & \multicolumn{4}{|c|}{ NÍVEL DE FDN } & \multirow[b]{2}{*}{$\mathrm{R}^{2}$} & \multirow[b]{2}{*}{$\mathrm{CV}(\%)$} & \multirow[b]{2}{*}{ ER } \\
\hline & 25 & 31 & 37 & 43 & & & \\
\hline PI & 20,26 & 20,09 & 18,66 & 18,31 & ---- & 14,94 & $Y=19,28$ \\
\hline PA & 30,84 & 31,52 & 30,11 & 30,92 & --- & 3,31 & $\mathrm{Y}=30,80$ \\
\hline Dias & 33,20 & 38,25 & 47,60 & 70,50 & 0,40 & 36,49 & 1 \\
\hline GMD & 0,321 & 0,318 & 0,239 & 0,188 & 0,60 & 17,23 & 2 \\
\hline $\mathrm{CA}$ & 3,04 & 3,13 & 3,28 & 4,21 & 0,65 & 19,04 & 3 \\
\hline
\end{tabular}

$1-$ Dias $=-11,04+1,75 \mathrm{FDN} * *$

$2-\mathrm{GMD}=0,498-0,007 \mathrm{FDN} * *$

3 - $\mathrm{CA}=1,52+0,057 \mathrm{FDN}^{*}$

* e ** significativo a 5 e $1 \%$ de probabilidade, respectivamente, pelo teste $\mathrm{F}$.

FDN = nível de fibra em detergente neutro da dieta. 


\section{AGRADECIMENTOS E APRESENTAÇÃO}

Ao Conselho Nacional de Desenvolvimento Científico e Tecnológico (CNPq), pela bolsa concedida aos pesquisadores Diego Barcelos Galvani e Cléber Cassol Filho.

Parte da Dissertação de Mestrado apresentada pelo primeiro autor à Universidade Federal de Santa Maria (UFSM), Santa Maria, RS, Brasil.

\section{REFERÊNCIAS}

ARAÚJO, G.G.L. et al. Consumo e digestibilidade total dos nutrientes de dietas contendo diferentes níveis de volumoso, em bezerros. Revista Brasileira de Zootecnia, v.27, n.2, p.345-354, 1998

BUENO, M.S. et al. Desempenho de cordeiros alimentados com silagem de girassol ou de milho com proporções crescentes de ração concentrada. Revista Brasileira de Zootecnia, v.33, n.6, p.1942-1948, 2004. (suplemento 2).

BÜRGER, P.J. et al. Consumo e digestibilidade aparente total e parcial em bezerros holandeses alimentados com dietas contendo diferentes níveis de concentrado. Revista Brasileira de Zootecnia, v.29, n.1, p.206-214, 2000

CARVALHO, S. Desempenho e comportamento ingestivo de cabras em lactação alimentadas com dietas contendo diferentes níveis de fibra. 2002. 118f. Dissertação (Doutorado em Zootecnia) - Curso de Pós-graduação em Zootecnia Universidade Viçosa.

FORBES, J.M. Voluntary food intake and diet selection in farm animals. Wallingford: CAB, 1995. 532p.

FURUSHO-GARCIA, I.F. et al. Desempenho de cordeiros Santa Inês puros e cruzas Santa Inês com Texel, Ile de France e Bergamácia. Revista Brasileira de Zootecnia, v.33, n.6, p.1591-1603, 2004.

GARCIA, I.F.F. et al. Características de carcaça de cordeiros Texel x Bergamácia, Texel x Santa Inês e Santa Inês Puros, terminados em confinamento, com casca de café como parte da dieta. Revista Brasileira de Zootecnia, v.30, n.3, p.253260, 2000 .

LOERCH, S.C. Dietas a base de concentrados para gado de corte. In: SIMPÓSIO SOBRE PRODUÇÃO ANIMAL, 9., 1997, Piracicaba, Anais... Piracicaba: FEALQ, 1997. p.135-160.

MACEDO, F.A.F. et al. Qualidade de carcaças de cordeiros Corriedale, Bergamácia x Corriedale e Hampshire Down x Corriedale, terminados em pastagem e confinamento. Revista Brasileira de Zootecnia, v.29, n.5, p.1520-1527, 2000.

MATOS, M.S.; MATOS, P.F. Laboratório clínico médicoveterinário. 2.ed. Rio de Janeiro: Atheneu, 1988. 238p.

MERTENS, D.R. Using Fiber and Carbohydrate Analyses to Formulate Dairy rations. In: Informational Conference with Dairy and Forages Industries, Us Dairy Forage Research Center, 1996.

MORENO, J.A. Clima do Rio Grande do Sul. Porto Alegre: Secretaria da Agricultura. 1961. 41p.

MOTTA, O.S. Ganho de peso, características da carcaça de cordeiros (as) em diferentes métodos de alimentação, peso de abate e produção de leite de ovelhas. 2000. $93 \mathrm{f}$. Dissertação (Mestrado em Zootecnia) - Universidade Federal de Santa Maria.

NATIONAL RESEARCH COUNCIL - NRC. Nutrients requeriments of sheep. 6.ed. Washington, D.C.: 1985. 242p.

NICHOLS, S.W. et al. Effects of fiber from tropical corn and forage sorghum silages on intake, digestion, and performance of lactating dairy cows. Journal of Dairy Science, v.81, n.9, p.2383-2393, 1998.

PIRES, C.C. et al. Cria e terminação de cordeiros confinados. Ciência Rural, v.30. n.5, p.875-880, 2000

PRESTON, R.L. Management of high concentrate diets em feedlot. In: CONGRESSO BRASILEIRO DE NUTRIÇÃO ANIMAL, 1998, Campinas. Anais... Campinas: CBMA, 1998. p.82-91.

RESENDE, F.D. et al. Rações com diferentes níveis de fibra em detergente neutro na alimentação de bovídeos em confinamento. Revista Brasileira de Zootecnia, v.22, n.3, p.366-376, 1994.

ROCHA, M.H.M. Teores de proteína bruta em dietas com alta proporção de concentrado para cordeiros confinados. 2002. 73f. Dissertação (Mestrado em Zootecnia) - Escola Superior de Agricultura "Luiz de Queiroz", Universidade de São Paulo.

SAS - Statistical Analiys System. User'sGuide. Versão 6, SAS INSTITUTE INC. 4.ed. North Caroline, 1997. 846p.

SILVA, D.J. Análise de alimentos: métodos químicos e biológicos. Viçosa, MG: Universidade Federal de Viçosa, 1990. $166 \mathrm{p}$.

SILVA, L.F.; PIRES, C.C. Avaliações quantitativas e predição das proporções de osso, músculo e gordura da carcaça em ovinos. Revista Brasileira de Zootecnia, v.29, n.4, p.1253-1260, 2000 .

SIQUEIRA, E.R.; FERNANDES, S. Efeito do genótipo sobre as medidas objetivas e subjetivas da carcaça de cordeiros terminados em confinamento. Revista Brasileira de Zootecnia, v.29, n.1, p.306-311, 2000.

SNIFFEN, C.J. et al. A net carbohydrate and protein system for evaluating cattle diets. 2. Carbohydrate and protein availability. Journal of Animal Science, v.70, n.11, p.3562-3577, 1992.

THIAGO, L.R.L.S.; GILL, M. Consumo voluntário de forragens por ruminantes: mecanismo físico ou fisiológico? In: Bovinocultura de corte. Piracicaba: FEALQ, 1990. p.4778

TURINO, V.F. Substituição da fibra em detergente neutro (FDN) do bagaço de cana-de-açúcar in natura pela FDN da casca de soja em dietas contendo alta proporção de concentrados para cordeiros confinados. 2003. $60 \mathrm{f}$. Dissertação (Mestrado em Zootecnia) - Escola Superior de Agricultura Luiz de Queiroz.

VAN SOEST, P.J.; MERTENS, D.R. The use of neutral detergent fiber versus acid detergent fiber in balancing dairy rations. In: TECHINICAL SYMPOSIUM, 1984, Fresno. Proceedings... Fresno: Monsanto - Nutrition Chemicals Division, 1984. p.7592.

Ciência Rural, v.36, n.1, jan-fev, 2006. 